PBAR Note 642

\title{
Design and Simulation Results of Waveguide Bends Used in Debuncher Cooling System
}

\author{
Ding Sun \\ $09 / 13 / 2000$
}

This note is a document about design and simulation results of waveguide bends installed with the arrays in debuncher cooling upgrade.

The main feature of these bends is that they are not traditional mitered bends or round bends. Instead, a cylinder is placed in the corner area of the bend. The reason for this design is purely to overcome some practical problems: (1) since these bends are very close to the slotted foil which serves as part of the waveguide array, it is very difficult to make good joint and contact if mitered bends are used, (2) assembly difficulty due to the location of these bends, and (3) limited space requires a compact design.

Shown in Figure 1 is a schematic drawing of a bend. Dimensions of bends for each frequency band are listed in Table 1. Shown in Figure 2-5 are the simulation results using HFSS. One of the bends was fabricated with flanges on both ends and measured using a Network Analyzer. The HFSS result was confirmed by the measured data.

Table 1. Dimensions of waveguide bends

\begin{tabular}{|l|l|l|l|l|l|}
\hline & Frequency & R (inch) & d (inch) & h (inch) & w (inch) \\
\hline Band 1 & $3.8-4.9 \mathrm{GHz}$ & 0.20 & 0.264 & 0.660 & 2.29 \\
\hline Band 2 & $4.7-5.8 \mathrm{GHz}$ & 0.17 & 0.225 & 0.535 & 1.87 \\
\hline Band 3 & $5.6-7.0 \mathrm{GHz}$ & 0.14 & 0.185 & 0.455 & 1.59 \\
\hline Band 4 & $6.8-8.2 \mathrm{GHz}$ & 0.12 & 0.155 & 0.395 & 1.37 \\
\hline
\end{tabular}

Note:

(1) w (not shown in Figure 1) is the width of the waveguide bend.

(2) Dimensions of bends used for Band 2 are different from listed in Table 1 due to an earlier version of the design: $\mathrm{R}$ is 0.15 and $\mathrm{d}$ is 0.175 . The performance is still very well: S11 is below $-22.5 \mathrm{db}$. 


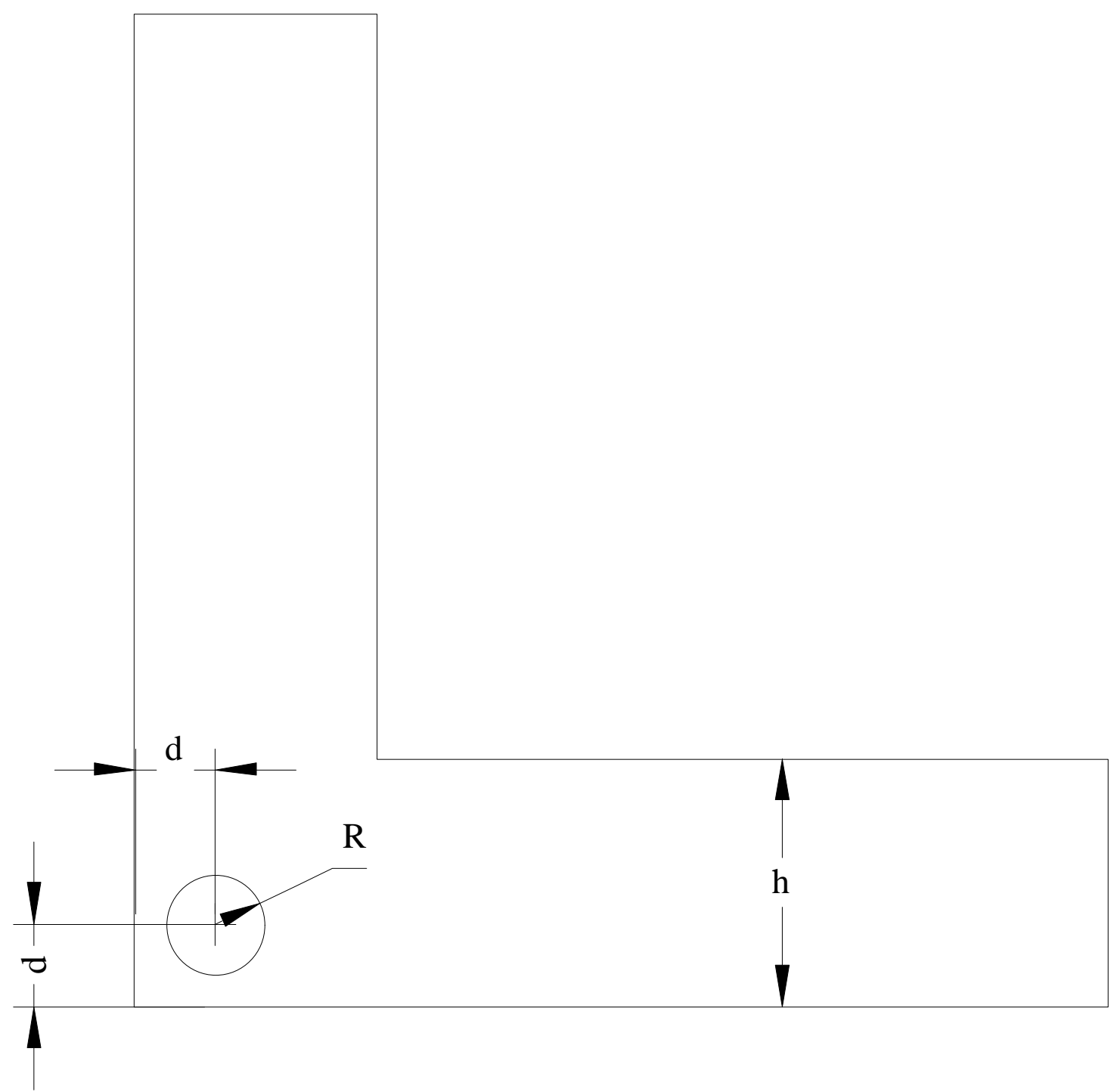

Figure 1. Schematic drawing of a waveguide bend 


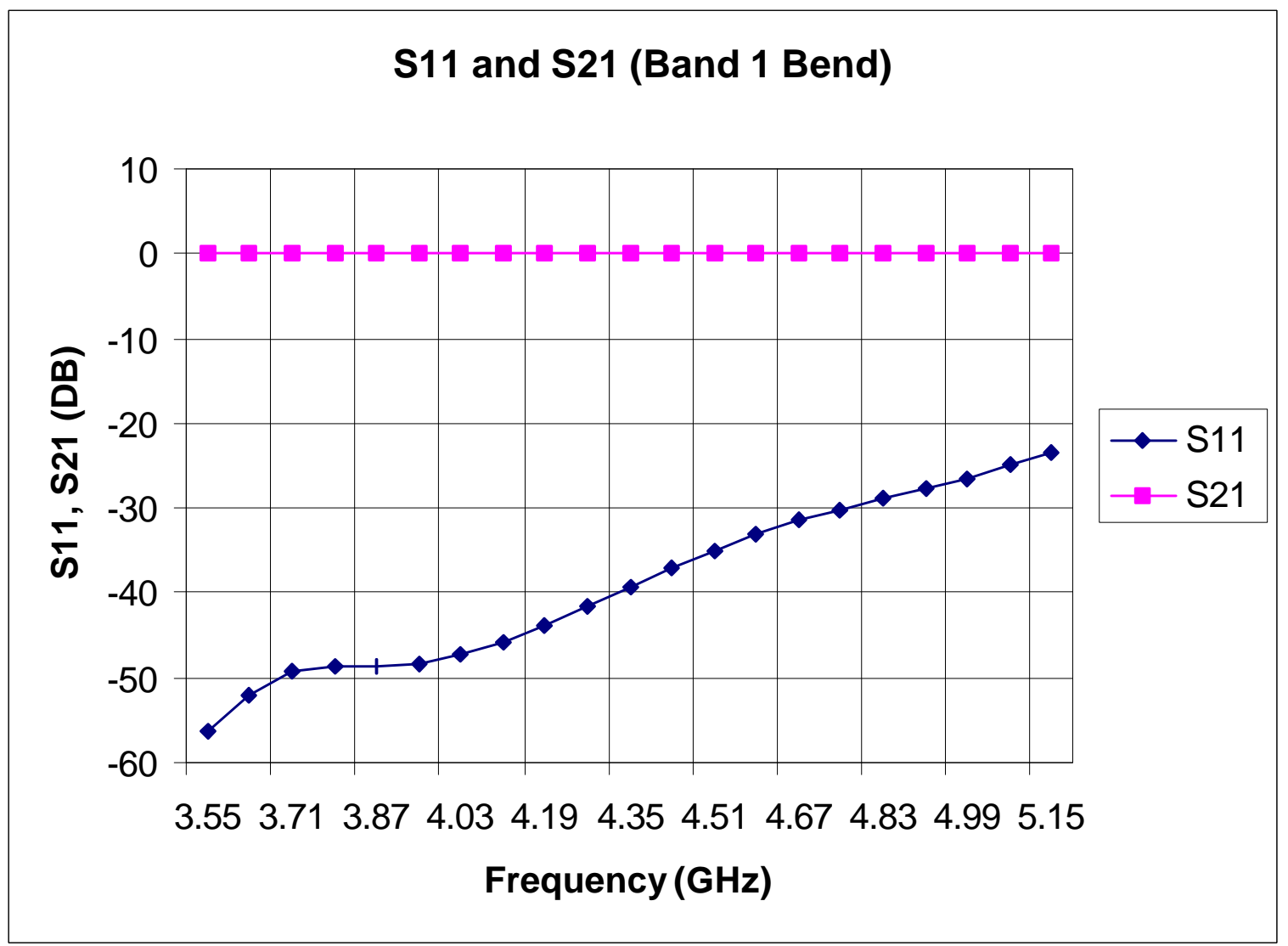

Figure 2. Simulation results of waveguide bend used for band 1 . 


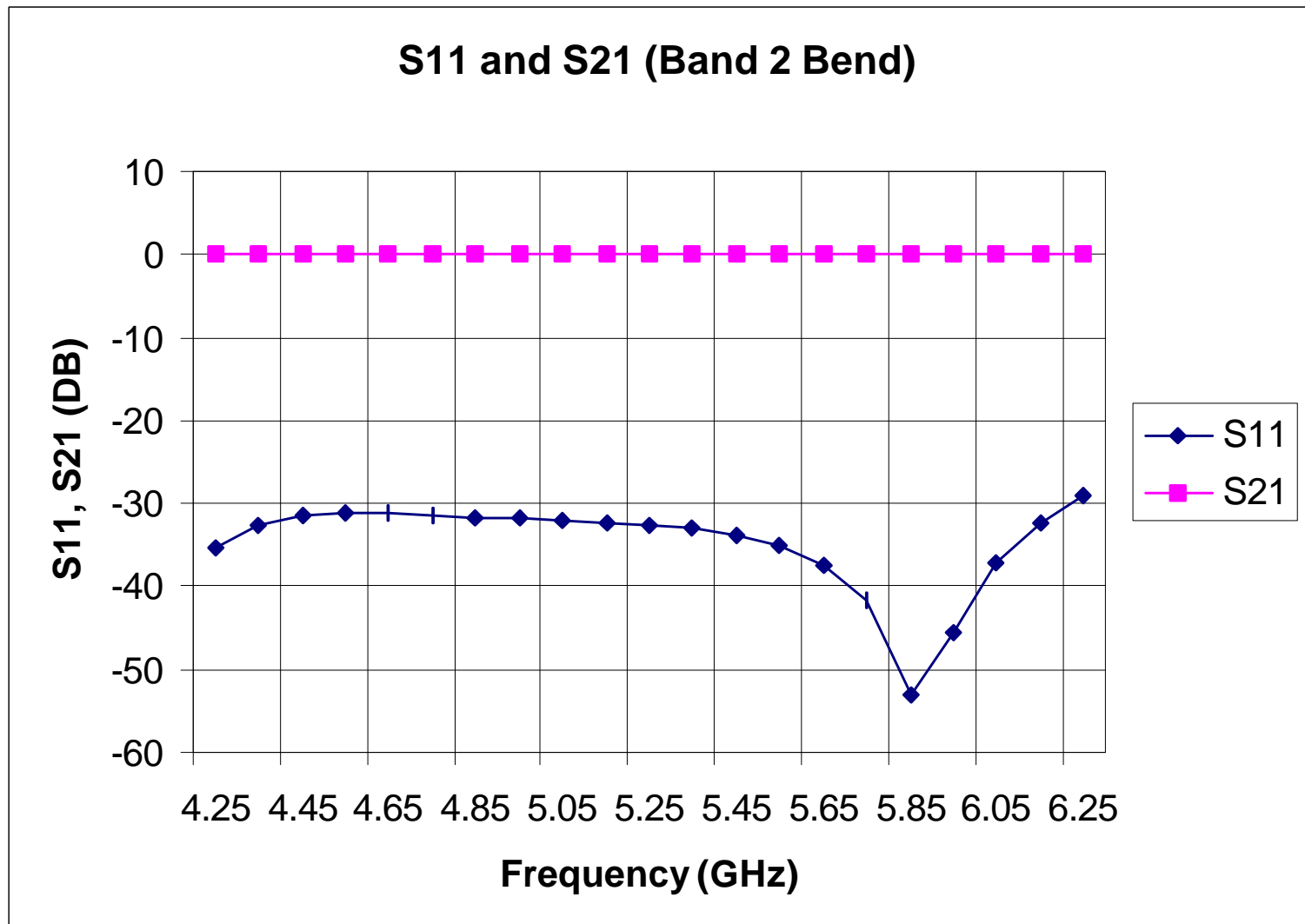

Figure 3. Simulation results of waveguide bend used for band 2 . 


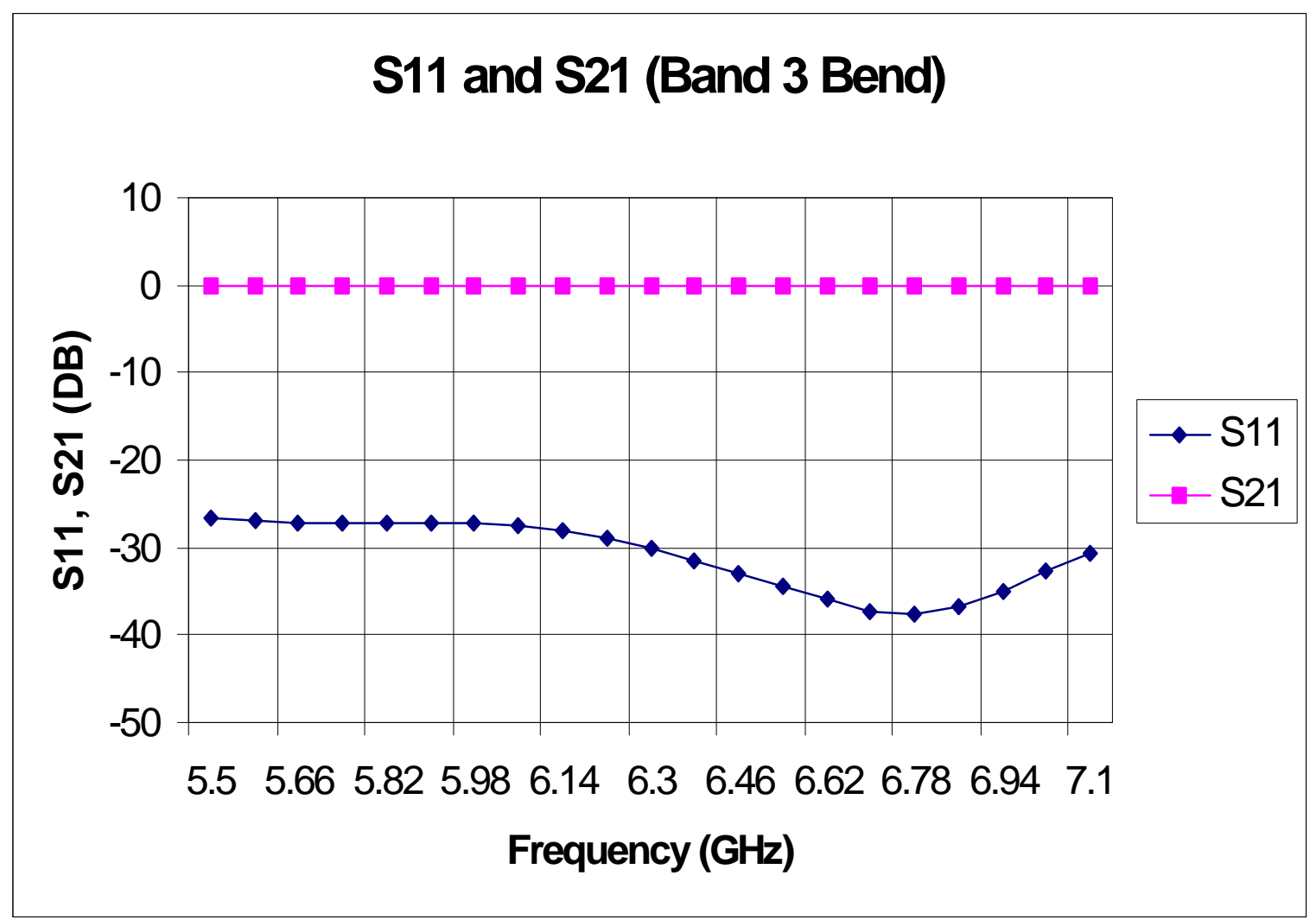

Figure 4. Simulation results of waveguide bend used for band 3 . 


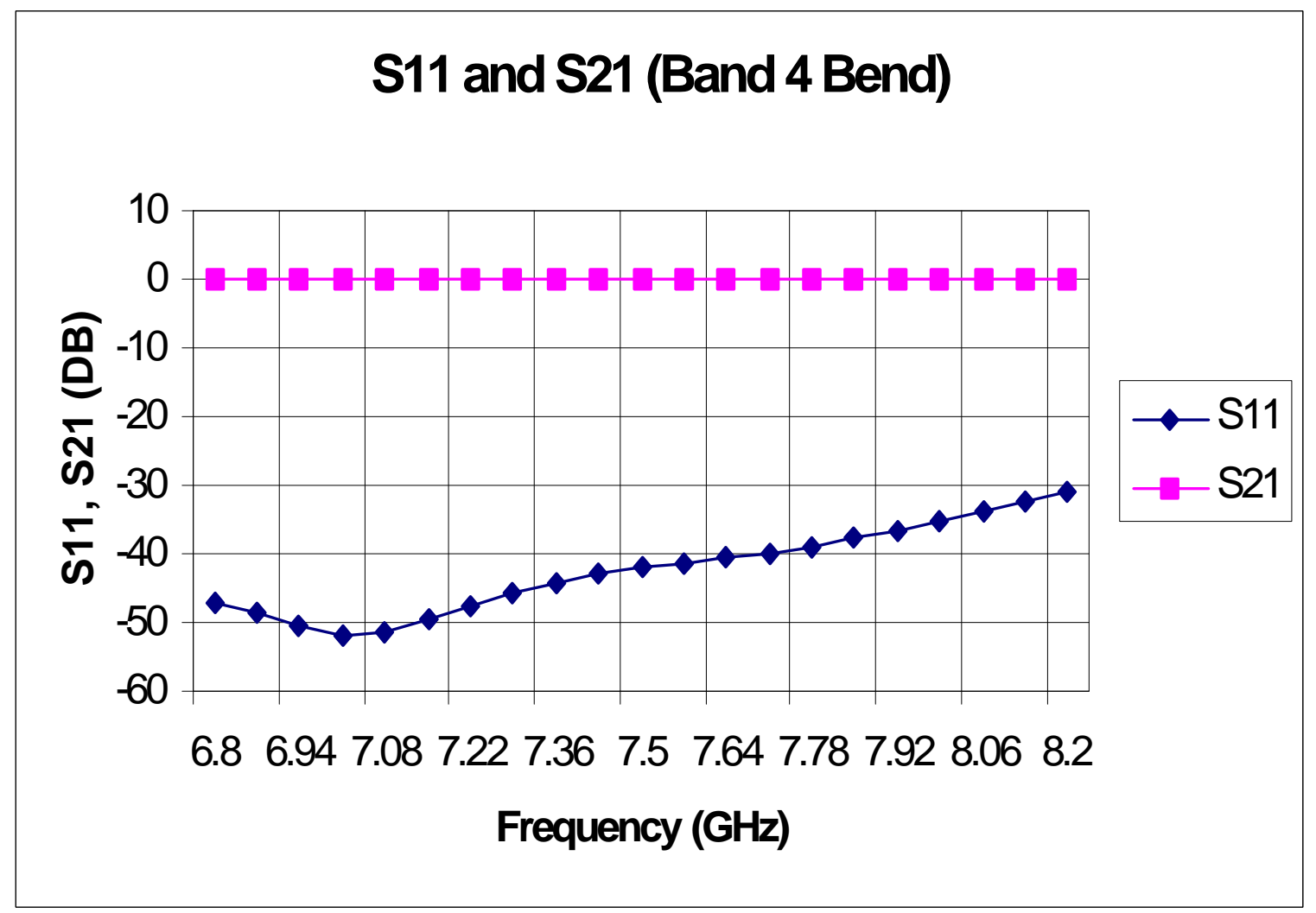

Figure 5. Simulation results of waveguide bend used for band 4 . 